\title{
Между верой и неверием: заметки о рукописи Е. Д. Паздерина «Воспоминания»
}

\author{
Маргарита П. Татаринцева \\ Тувинский институт гуманитарных и прикладных социально-экономических исследований \\ при Правительстве Республики Тыва, Российская Федерация
}

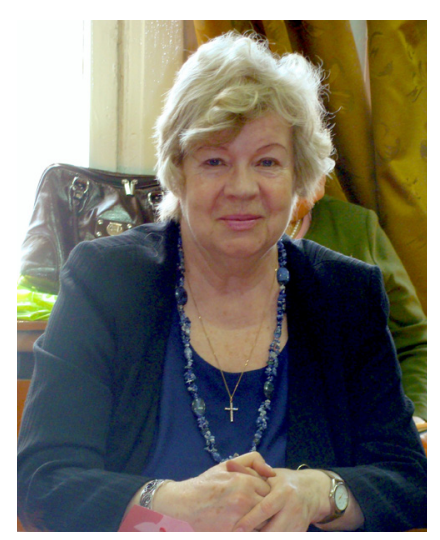

В статье анализируется рукопись Е. Д. Паздерина (1902-1980) «Воспоминания» о жизни русских переселенцев-старообрядцев в Туве, в верховье Малого Енисея в первой половине XX в. Она хранится в научном архиве Тувинского института гуманитарных и прикладных социально-экономических исследований с 1977 г.

По вероисповеданию старообрядец, автор подробно рассказал о своей жизни в среде одноверцев в 1920-1940-е годы, об эволюции своих взглядов на религию и в конечном счете переход на позиции активиста, общественника-пропагандиста, борца с религиозными предрассудками. Привлекает не только необычная судьба автора рукописи, но и множество приводимых им фактов, событий, подробностей, имевших место в Верховье и неизвестных исторической науке по другим источникам. Дано подробное описание образа жизни старообрядцев Верховья, первоначально их неоднородный конфессиональный состав, раскрыта система самообеспечения в новых условиях, взаимоотношения с коренным населением, протесты и способы противостояния антирелигиозному натиску со стороны государства, в котором старообрядияы видели приход Антихриста и др. Автор всему дает свое объяснение и оценку, которые в статье также подвергаются анализу и в некоторых случаях переоценке.

Сомнения и колебания постоянно сопровождают автора «Воспоминаний», в конечном счете это вылилось в его отход от веры, хотя сам он до смерти так и жил в старообрядческой деревне.

Сочинение Е. Паздерина сравнивается с другим произведением тоже самодеятельного автора - книгой старообрядки Н. Г. Сидоркиной под названием «Заповедная вера. Книга жития и страданий сымских старообрядиев» (2002 г.). Судьба ее автора соответствует истории Е. Паздерина «с точностью до наоборот»: путь от неверия к крепкой вере.

Ключевые слова: Тува; старообрядцы; старообрядцы Тувы; Верховье; старая вера; часовенное согласие; Каа-Хем

\footnotetext{
Татаринцева Маргарита Петровна - кандидат филологических наук, ведущий научный сотрудник отдела истории Тувинского института гуманитарных и прикладных социально-экономических исследований. Адрес: 667000, Россия, г. Кызыл, ул. Кочетова, д. 4. Тел.: +7 (394-22) 2-39-36. Эл. адрес: margotatar@mail.ru
}

TATARINTSEVA, Margarita Petrovna, Candidate of Philology, Leading Research Fellow, Department of History, Tuvan Institute of Humanities and Applied Socio-Economic Research under the Government of the Republic of Tuva. Postal address: 4 Kochetov St., 667000 Kyzyl, Russian Federation. Tel.: +7 (394-22) 2-39-36. Email: margotatar@mail.ru 


\title{
Between faith and unbelief: Notes on E. D. Pazderin's manuscript “Memoirs”
}

\author{
Margarita P. Tatarintseva \\ Tuvan Institute of Humanities and Applied Socio-Economic Research \\ under the Government of the Republic of Tuva, Russian Federation
}

\begin{abstract}
The article takes a close look at E. D. Pazderin's (1902-1980) "Memoirs" - a manuscript describing the life of Russian Old Believer settlers in Tuva, in the upper reaches of the Maly Yenisei in the first half of the 20th century. Since 1977, the manuscript has been preserved in the research archive of Tuvan Institute of Humanities and Applied Socio-Economic Research under the Government of the Republic of Tuva.

Born to an Old Believer family, the author provided a detailed narrative of his life in Old Believer community from the 1920s to the 1940s, of the subsequent evolution of his religious views and his ultimate transformation into an activist, a propagandist who condemned "religious prejudice". Besides the author's biographical twists, the manuscript covers a multitude of facts, events and developments in Verkhovye, which were unknown to historical science from any other source. In describing the lifestyle of the Old Believers' community, Pazderin focuses on their confessional non-uniformity, their self-sustainability under new living conditions, on their contacts with the indigenous population, on protests and self-defense of Old Believers against the anti-religious policy of the government (which Old Believers saw as the Anti-Christ). Pazderin provides an explanation and assessment to every detail, often reassessing them later.

The author of the "Memoirs" was always beset with doubts and hesitation, which ultimately led to his loss of faith, although he never moved out of his Old Believer village, where he lived until his death.

In this article, Pazderin's memoirs are compared with another manuscript by a non-professional author - N. G. Sidorkina's "Zapovednaia vera. Kniga zhitiia i stradanii symskikh staroobriadtsev" "Sacred faith. The book of life and sufferings of the Old Believers of Sym"]. Also an Old Believer, Pazderina evolved in the opposite way: from unbelief she moved to strong devotion.
\end{abstract}

Keywords: Tuva; Old Believers; Old Believers in Tuva; Verkhovye; Old Belief; Chasovennoe accord; Kaa-Khem

For citation:
Tatarintseva M. P. Mezhdu veroi i neveriem: zametki o rukopisi E. D. Pazderina «Vospominaniia» [Between faith and
unbelief: Notes on E. D. Pazderin’s manuscript “Memoirs”]. New Research of Tuva, 2021, no. 3, pp. 90-98. (In Russ.). DOI:
https://www.doi.org/10.25178/nit.2021.3.7

\section{Введение}

В статье анализируется интереснейший документ, относящийся к первой половине XX века - о жизни русских переселенцев-старообрядцев в Туве, в верховье Малого Енисея. Речь идет о рукописи Евлампия Дмитриевича Паздерина (1902-1980) под названием «Воспоминания», переданной автором в научный архив Тувинского института гуманитарных и прикладных социально-экономических исследований (ТИГПИ, тогда - Тувинский научно-исследовательский институт языка, литературы и истории - ТНИИЯЛИ) в 1977 г. Рукопись хотя и известна историкам и краеведам (Рыговский, 2018 и др. $\left.{ }^{1}\right)$, однако, по нашему мнению, должного внимания и оценки она так и не получила. В наше время, когда устойчиво проявляется интерес к «тувинскому заповеднику старой веры», стоит обратить внимание на этот документ эпохи, написанный свидетелем и участником событий, происходивших в Туве в первой половине XX века, а также на личность самого автора, судьба которого сложилась неординарно и эту эпоху отразила.

${ }^{1}$ Емельянов А. Ф. От мира не уйти: Документальные повести и очерки. Кызыл: Тувинское книжное издательство, 1984. 239 с. 
По вероисповеданию старообрядец, автор подробно рассказал о своей жизни в среде одноверцев в 1920-1940-е годы, об эволюции своих взглядов на религию и в конечном счете переход на позиции активиста, общественника-пропагандиста, борца с религиозными предрассудками. Привлекает не только необычная судьба автора рукописи, но и множество приводимых им фактов, событий, подробностей, имевших место в Верховье и неизвестных исторической науке по другим источникам. Автор всему дает свое объяснение и оценку, которые в статье также подвергаются анализу и в некоторых случаях переоценке. Сомнения и колебания постоянно сопровождают автора «Воспоминаний», в конечном счете это вылилось в его отход от веры, хотя сам он до смерти так и жил в старообрядческой деревне, в среде «ортодоксальных» староверов, как называют современные исследователи Верховье (Костров, Пригарин, 2018).

В статье сделана попытка разобраться с этим феноменом. Помимо этого, мы проводим параллель: сочинение Е. Паздерина сравнивается с другим произведением тоже самодеятельного автора книгой старообрядки Н. Г. Сидоркиной под названием «Заповедная вера. Книга жития и страданий сымских старообрядцев» (2002 г.). Судьба ее автора соответствует истории Е. Паздерина «с точностью до наоборот»: путь от неверия к крепкой вере, которая, по мнению Сидоркиной, и помогает жить и выживать человеку даже в самых суровых условиях (Пригарин, Стороженко, Татаринцева, 2020).

Рукопись Е. Д. Паздерина представляет собой три толстых общих тетради в клеточку, объемом 209 страниц, написанных от руки. Впоследствии работниками архива текст был перепечатан на машинке и его объем составил 80 страниц. Текст самим автором не структурирован, порой даже аморфен, но при знакомстве с ним он четко распадается на две неравные части: история жизни и отношения с единоверцами-старообрядцами самого автора - это большая и самая ценная часть воспоминаний, и история колхоза «Буренский», который помогал создавать сам автор и в котором жил до самой смерти (село Бурен-Бай-Хаак Каа-Хемского района республики). Таким образом, по времени рукопись охватывает период, начиная с 1917 г., когда Е. Д. Паздерин впервые приехал в Туву, до периода 1940-х годов, когда Тува вошла уже в состав СССР и была охвачена грандиозными переменами коллективизацией и переходом аратов на оседлый образ жизни.

Следует отметить, что в своих воспоминаниях автор весьма конкретен - он рассказывает только о том, что видел сам, что происходило на территории Каа-Хемского района, по большей части в верховье Малого Енисея, у него в тексте нет общих мест и пафосных рассуждений, хотя он на склоне лет был корреспондентом местных газет, пропагандистом и агитатором.

\section{Мотивы написания «Воспоминаний» и их научное значение}

Археографы, изучающие книги самодеятельных писателей-старообрядцев, называют ряд побудительных причин этих авторов взяться за перо: желание изложить постулаты старой веры для современников и потомства, рассказать о подвижнической жизни единоверцев, о противостоянии древлеправославных враждебно настроенному против них государству и многое другое (Покровский, 1984; Зольникова, 1992, 1998; Покровский, Зольникова, 2002; Шитова, 2013). Однако, учитывая время начала работы над воспоминаниями Е. Паздерина, как он сам датирует - 1947 г. (а ему в это время было 45 лет), причины взяться за перо у него скорее всего были другие.

Автор хотел рассказать поучительную историю о своей жизни, о пути, который он прошел сам - от веры к неверию, от почти необразованного, ничем не примечательного паренька, да еще одноглазого (в детстве из-за несчастного случая потерял глаз), - до активиста-общественника, застрельщика новых начинаний, уважаемого властью человека.

Известно, что на просторах СССР и в писательской среде, и в среде простых людей, обладающих определенным жизненным опытом, был чрезвычайно популярен жанр автобиографической прозы, и расцвет этой популярности совпал со временем выхода трилогии М. Горького «Детство», «В людях» (1913-1916), «Мои университеты» (1922). За собственное жизнеописание взялись многие люди, прошедшие войны и революции. Думается, что и Е. Паздерин, в то время уже имевший опыт написания заметок и статей в газеты, подпал под это влияние. Как верно подметила Е. Е. Дутчак, некоторыми авторами с помощью подобного жизнеописания «предпринимается попытка упорядочить свою собственную жизнь» (Дутчак, 2008: 288). Скорее всего, «Воспоминания» Е. Паздерина преследовали и эту цель. Отдельные штрихи и особенности в изложении событий собственной жизни указывают, что автор претендовал на некую художественность, но его возможности ограничивались попытками описаний прекрасной суровой природы края. Психологические характеристики развернуть автору не 
удалось, хотя на его жизненном пути встречались уникальные действующие лица, да и более глубокий самоанализ перехода от веры к неверию помог бы ему убедительнее обосновать этот феномен.

Для нас эта рукопись представляет документальную, научную ценность, по форме это нечто среднее между дневником, мемуарами и летописной фиксацией событий и фактов. Подкупает то, что автор нигде не пытается выставить себя в лучшем свете, промолчать о своих ошибках и поражениях, сомнениях и метаниях. Последнее касается его религиозной жизни, тем более его путь от крепкой веры к неверию происходил в окружении истово верующих старообрядцев, которые в это же самое время, в этих же условиях, при том же жестком давлении властей сумели сохранить устои старой веры, да так, что даже в XXI веке исследователи называли старообрядцев Верховья «ортодоксальными» (Костров, Пригарин, 2018).

Для историков, этнологов и религиоведов это, пожалуй, самая ценная часть воспоминаний, поскольку, во-первых, они относятся к раннему времени жизни староверов в Туве, о котором в других источниках мало осталось конкретных сведений, и, во-вторых, порой несут в себе несколько неожиданные сведения, например, о многочисленности мелких толков в Верховье в 1920-е годы при общей немногочисленности старообрядческого населения, о формах протеста против действий «безбожного» государства и др.

Для исследователя старообрядчества представляют интерес страницы с описанием образа жизни, способов жизнеобеспечения переселенцев-старообрядцев, а также эпизоды, связанные с Гражданской войной и взаимоотношений с коренным населением Каа-Хема (впрочем, не столь многочисленного, как в западных хошунах Тувы). Т. е. рукопись несет в себе ценную, по времени наиболее раннюю информацию о старообрядцах верховья Малого Енисея, изложенную самим бывшим старообрядцем. Особый интерес вызывают описания автора с попытками самоанализа о том, каким испытаниям подвергалась его вера и под влиянием каких обстоятельств происходила трансформация его сознания, как он перешел в стан неверующих. Причем происходило это не только из-за внешнего давления - воинствующей атеистической пропаганды, стремительно меняющегося образа жизни с переоценкой ценностей, но и по причинам внутреннего несогласия с поступками единоверцев он видит в их поведении корысть, обман, несправедливость, т. е. те человеческие пороки, которые противоречат вероучению, которые они сами же в других осуждают. Конечно, на первых порах в его суждениях и оценках сказывается юношеский максимализм, завышенные требования к тем, кто молится с утра до вечера, стремясь попасть в рай, а потом точно так же грешит, как и все остальные грешники.

\section{Путь с Алтая в Туву}

Пятнадцатилетним подростком Е. Паздерин перебирается на постоянное жительство с Алтая в Туву по настоянию своей бабушки. Именно она приучила его молиться и верить в Бога, поскольку к этому времени он лишился отца и матери, жил с мачехой в обстановке, «где не верили ни в бога, ни в черта». Заботящаяся о душе внука богобоязненная бабушка решила отправить его к своему крайне религиозному сыну (дяде Е. Паздерина), проживающему в Туве, в верховье Малого Енисея, и полностью посвятившего свою аскетическую жизнь отшельника спасению души, молитвенному общению с Богом.

Тысячекилометровый путь в Туву вслед за гружеными лошадьми занял 32 дня. Автор рукописи довольно подробно описывает этот путь, населенные пункты - деревеньки и заимки, где приходилось останавливаться на ночлег, а так как ночевали у старообрядцев, то автор характеризует скупыми штрихами их жизнь, быт, обычаи и т. д., что позволяет составить представление людях этой конфессии, дисперсно расселившихся на бескрайних просторах Сибири. Например, каковы правила гостеприимства, чашечничество ${ }^{1}$, запрет пить колодезную воду и др. С одними хозяевами путники ужинали вместе, ночуя у других варили себе еду сами, одни требовали плату за ночлег и корм коней, другие делали это бесплатно и т. д. Зимний месячный путь в Туву - это тоже интересная картина жизни сибирской глухомани и сложности взаимоотношений старообрядцев разных толков между собой и с внешним миром.

\footnotetext{
${ }^{1}$ Правило есть только из своей посуды - чашки, принятое у старообрядцев часовенного согласия (см.: Рыговский, 2018: 172).
} 
Путники беспрепятственно преодолели границу с Тувой, проехали ночной Кызыл, где светились лишь окошки казарм казаков, а далее на их пути лежали Зубовка, Федоровка, ныне носящие другие названия. Автор называет фамилии обитателей этих деревень, они и сегодня известны в КааХеме, хотя их потомки давно сменили место жительства. Далее на пути в Верховье лежали Терсик, Бельбей, другие заимки, основанные старообрядцами, названия которых не исчезли с карты до сих пор. Конечной целью столь продолжительного путешествия было поселение Чодуралыг (по-русски Чедралыг, так в тексте источника).

\section{Монашеский образ жизни в семье дяди}

Вблизи Чедралыка в местечке Ине куль (ийи хөл, тув. - 'два озерка') располагалось жилище дяди Автонома Ермолаевича Юркова, у которого должен был жить Евлампий. Дядя скрывался в тувинской тайге, уклоняясь от призыва на военную службу во время Первой мировой войны. Дорога к Чедралыку еще большая таежная глушь - ознаменовалась событием, оценить значение которого автор смог значительно позже: произошла неожиданная встреча с тувинцами, в том числе с молодым С. Токой, будущим руководителем Тувы. Дано первое описание этого деятеля в юношеском возрасте (он лишь на два года старше Е. Паздерина), тогда он был батраком Степана Михайлова и, как рассказывали земляки, отличался активностью, хорошо говорил по-русски и хорошо умел петь старообрядческие стихеры (НА ТИГПИ, т. 714, с. 8).

Наконец, цель поездки достигнута. Примечательно описание правил бытового обхождения у старообрядцев, самого отшельнического жилища, режима жизни, близкого к монашескому (хотя отшельники-дядя и тетка, их сын - не принимали монашеского пострига). Вот описание землянки дяди, которую они называли «келья»:

«Келья... была не побелена, на потолке паутина, стены и потолок были черными. Посреди кельи стояло корыто, в котором лежала лучина, приготовленная для освещения... В переднем углу стоял налой, на котором лежала толстая книга. На полочке стояли иконы, медные и деревянные. В другом углу - русская печь. В куте стояла деревянная кадка с водой и несколько глиняных горшков, два котелка жестяные. В одном углу на веревочке висел туесок, из которого умывались. На полу стояли две скамейки, стол на крестовине. Вместо окна была прорублена дыра, в которую было вставлено стекло. Балка лежала наверху круглая, потолок был настлан на два ската из плах неотесанных» (НА ТИГПИ, т. 714. с. 9-10).

Так как рассказ о жизни и бытовом укладе семьи дяди дается по прошествии чуть ли не полвека, с тех пор мировоззрение автора сильно изменилось и в воспоминаниях появились осуждающие оценки, в частности, в отношении его к сироте-племяннику:

«Все сколько-нибудь ценные предметы моей одежды... были проданы, выменяны или каким-либо иным образом использованы всей семьей, сам же я, как и они, стал носить домотканные холщевые штаны и рубаху, подпоясанную веревочкой» (НА ТИГПИ, т. 714, с. 10).

«2/3 времени дядя проводил на молении... 1000 поклонов в день для монахов «правило»: 300 земных и 700 в пояс. Я тоже начал молиться, подражая дяде, так хотелось попасть в рай. С лестовкой не расставался» (НА ТИГПИ, т. 714, с. 14).

Примечательно, что колебания - от желания вести почти монашеский образ жизни, чтобы спасти душу и попасть в рай, до сомнений в вере и переход к жизни мирской - будут сопровождать Е. Паздерина долгие годы.

Вызывают интерес немногие страницы рукописи, в которых рассказывается о контактах староверовпереселенцев с коренным населением. Как живут таежные тувинцы Евлампий узнал, побывав в Чедралыке, наподалеку от которого жили две тувинские семьи - Сегбе и Ак-оола.

Описание их жизни и быта очень сочувственное и сильно напоминает страницы повести С. К. Тока «В берестяном чуме»: «Ужасающая бедность, заваривали лиственничную кору вместо чая» ${ }^{1}$ (НА ТИГПИ, т. 714, т. 14) (кстати, место действия то же, что и у С. Тока - верховье Малого Енисея»). Евлампий общался с этими семьями, постепенно научился говорить с ними по-тувински.

Посещение Чедралыка имело судьбоносное значение для автора, здесь он встретил Е. А. Курносенко, которого всю последующую жизнь считал главным человеком в своей жизни (к сожалению, тот в годы гражданской войны погиб от рук бандитов). «Безбожник» Курносенко своими личными качествами, желанием помочь слабому, стремлением во всем поступать по справедливости так сумел воздействовать

${ }^{1}$ Тока С. К. В берестяном чуме / пер. с тувинского А. Темира и С. Пюрбю ; предисл. Степана Шипачева. М. : Советский писатель, 1943. 52 с. 
на юношеское сознание Евлампия, что стал для него нравственным авторитетом, и тот решает остаться у Курносенко, жить по-мирски, даже несмотря на увещевания дяди (тот раз 15 кланялся ему в ноги, умоляя племянника вернуться к прежней жизни).

\section{Самостоятельная жизнь в среде одноверцев}

Итак, за годы совместной жизни в семье Курносенко автор постепенно отходил от усердного молитвенного служения Богу, вера его слабела и почти сошла на нет. У него сформировалась вера в собственные силы, в помощь самых близких людей. Но он жил в том же окружении, которое реагировало на его отход от веры, предъявляло свои требования к поведению «заблудшей овцы». Тем более, что ему всегда было свойственно резко реагировать на обман и несправедливость, а смирение не входило в число его добродетелей.

В молодом возрасте крепкие в вере односельчане пробовали вернуть его в общину с помощью плетей, проучив за нарушение правил, а позже просто открыто пренебрежительно называли безбожником. Между тем Е. Паздерин замечает многие особенности жизни староверов Верховья: в частности, именно от него мы узнаем, что изначально, в первые годы его жизни в Верховье, староверы не были едины в конфессиональном отношении, мелких толков было много:

«...в Верховье жило народу около 100 человек, все они были старообрядцы, но они делились на ответвления. Почти каждая семья молилась отдельно, одни с другими не кушали, каждый считал себя чистым и святым. Мы проводили службу без пения, чтением псалтыри, крестились и кланялись. Остальные службу справляли с пением, как в православной церкви» (НА ТИГПИ, т. 714, с. 14);

«Были и такие, что не признавали браки. Рукавицын Федор своему сыну запрещал жениться» (НА ТИГПИ, т. 714, с. 32).

Сейчас, напомним, в верховье Малого Енисея компактно проживают в основном старообрядцы часовенного согласия, преобладающие по всему «енисейскому меридиану» - течению Енисея с юга на север (Стороженко, 2019).

Как уже отмечалось, автор рукописи предельно честен по отношению к себе, в том числе и тогда, когда рассказывает о своей религиозной жизни. Прошло несколько лет мирской жизни, и религиозное окружение снова начинает влиять на Е. Паздерина:

«Я не имел никакого образования, монахи снова стали не давать мне покоя, я снова попал под влияние религии, стал активным верующим, выступал на собраниях верующих, стал активно молиться, так прошло у меня около 10 лет. Я читал много религиозных книг. Но появились сомнения. У меня было шестеро детей, осталась одна, остальные померли. Бог не помог. В Верховье неверующих не было, посоветоваться было не с кем. Мне жаль этих 10-ти лет, которые я прожил неправильно. После этого я много проводил бесед, читок на антирелигиозные темы. На молодежь хорошо влияла моя пропаганда, на пожилых - не особенно» (НА ТИГПИ, т. 714, с. 32).

К этому времени относится рассказ Е. Паздерина о многочисленных жертвах сторонников старой веры по причине усиления давления властей. Они уклонялись от переписи, прививок, паспортизации, призыва в армию, видя во всем этом пришествие Антихриста. Фанатично верующие топились, замерзали всей семьей, уйдя в непроходимую тайгу и пещеры, сжигали себя и т. д. Как считает Е. Паздерин, в Верховье в общей сложности покончило самоубийством 65 человек, среди них были и дети. Дан перечень семей, в которых произошли эти трагические события (НА ТИГПИ, т. 714, с. 36-41).

Факты в изложении Паздерина (1977 г.) стали достоянием общественности - ученых-историков раньше, чем появилась известная книга А. Емельянова, имевшая значительный общественный резонанс, излагающая эти же истории - 1978 г. ${ }^{1}$ Однако ни у того, ни у другого автора не прозвучала оценка неуклюжих и безграмотных действий властей, вызвавших неожиданную для них ответную реакцию у этой особой этноконфессиональной группы населения.

Значительное внимание в рукописи уделяется истории преобразований в Туве,для автора - сельского жителя - это коллективизация и переход аратов на оседлость. Е. Паздерин - один из активистов Каа-Хемского района в пропаганде колхозного движения, сам не раз оказывался руководителем разных бригад, организаций, подразделений, с энтузиазмом рассказывает о технических новшествах

${ }^{1}$ Емельянов А. Ф. От мира не уйти: Документальные повести и очерки. Кызыл: Тувинское книжное издательство, 1984. 239 с. 
и успехах, передовиках труда и наградах. Но опять-таки, надо отдать должное автору, который признается, что не раз в эти годы ему приходилось уходить с руководящих постов по причине малограмотности, отсутствия нужного опыта, несоответствия занимаемой должности. Внимательное прочтение этой части рукописи показывает, что основу колхоза «Буренский» составляли аратские хозяйства, тувинские фамилии фигурируют и среди передовиков и награжденных, а основное русское население района - старообрядцы - почти не упоминаются в победных реляциях активиста коллективизации, староверы в большинстве оставались единоличниками.

\section{Сравнение рукописей}

Хотелось бы сравнить рукопись Е. Паздерина, на наш взгляд искреннюю и самокритичную, с другим произведением автора-старообрядца, тоже автобиографическим - книгой Н. Сидоркиной (еще не опубликованной) -«Заповедная вера. Книга жития и страданий сымских старообрядцев» ${ }^{\text {. }}$

Автор сравниваемой рукописи принадлежит к титовскому согласию, отпочковавшемуся от часовенного, в настоящее время живет на Сыме (левый приток Енисея) и в своей книге, помимо изложения основ религиозного учения, затрагивает много тем, связанных с жизнью староверов в таежноболотистой местности, удаленной от цивилизации.

Хотя по времени событий сравниваемые рукописи отделяет более полувека - у Е. Паздерина это 1917-1940-е годы, а у Н. Сидоркиной -последнее десятилетие XX в., обе рукописи можно рассматривать как оригинальные старообрядческие сочинения нового времени. Общее в них и то, что оба автора превратили свою жизнь в окружении старообрядческого сообщества в исследование этого сообщества «методом включенного наблюдения». Внутренний диалог, автоэтнографические рефлексии присущи обоим авторам, их отличает предельная искренность и самокритичность в изложении событий и собственных переживаний.

Но если Е. Паздерин проходит путь от веры к неверию и желает поделиться своим опытом с потомством, то Н. Г. Сидоркина, напротив, прошла путь от неверия к крепкой древлеправославной вере. Повествование у Сидоркиной - это взгляд внутрь себя, осмысление на собственном опыте, как человек приходит к вере и что ему дает эта вера. Имея высшее образование, некоторый опыт научной работы, молодая женщина поняла при знакомстве со старообрядцами, их верой, их образом жизни, обычаями, что жить в этой вере и по ее законам - это то, что требует ее душа. Общение с наставником, изучение богословских книг, жизнь десятилетиями в семье по старообрядческому укладу сделала Н. Г. Сидоркину большим знатоком, в какой-то мере исследователем и, можно сказать, апологетом древлеправославия. Ее книга - это попытка разобраться с собственным опытом приобщения городского образованного человека к совершенно другой жизни, суровой и трудной, которая по силам далеко не каждому. Тем не менее, книга Н. Г. Сидоркиной не внушает пессимизма по поводу того, что не каждому дано пройти этот путь, напротив, при ее посыле «Все от Бога. Все в руках Божьих» возникает ощущение огромного жизненного потенциала у верующего человека, который с Божьей помощью может преодолеть все².

Е. Паздерин же к моменту окончания работы над рукописью предстает человеком неверующим, апологетом государственных нововведений, борцом с религиозными предрассудками, корреспондентом «Тувинской правды». Однако сложившееся представление об авторе дает возможность предположить, что его отход от религии может быть и не окончательным. Его путь - человека ХХ века, прошедшего через горнила войн и революций, голода и репрессий, потрясений и разочарований, это путь человека, которого судьба не раз ломала через колено. Вспомним стихи В. Соколова, поэта, в творчестве далекого от религиозных мотивов, но они о том же: как жизнь меняет-ломает человека, как «выгорает» его душа.

\footnotetext{
${ }^{1}$ Сидоркина Н. Г. Заповедная вера. Книга жития и страданий сымских старообрядцев (рукопись 2019 года). Хранится в рукописном фонде кафедры Отечественной истории Тувинского государственного университета (см.: Пригарин, Стороженко, Татаринцева, 2020).

${ }^{2}$ Сидоркина Н. Г. Заповедная вера..., л. 78.
} 


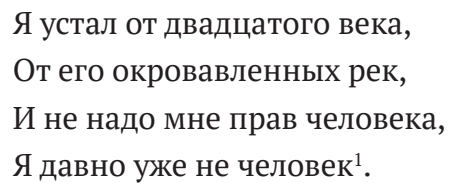

Если попытаться сделать вывод по результатам рассмотрения рукописей в сравнительном плане, то можно сказать, что помимо всего прочего мы видим в них отражение культурного феномена $\mathrm{XX}$ века - духовных исканий народа, и в рукописях показаны два наиболее типичных варианта этих исканий - приход к вере и отход от нее.

\section{Заключение}

Эвристическая ценность рукописи Е. Паздерина «Воспоминания» представляется нам в том, что она является уникальным источником сведений о жизни, религиозной и культурной специфике старообрядцев-беспоповцев часовенного согласия, ныне представленного по всему течению Енисея как мощный конфессиональный организм, на раннем этапе их переселения в Туву. Описание их жизни, религиозной и хозяйственно-бытовой, дано не глазами стороннего человека, не извне, а изнутри, что укрепляет уверенность в достоверности информации.

Некоторые представления можно составить о взаимоотношениях этого закрытого общества с коренными жителями, сведения об этом в других источниках также крайне скудны.

Интерес вызывает и личность самого автора, его жизненный путь. Нетипичным является факт трансформации сознания автора, его переход к неверию. Многолетние полевые наблюдения чаще показывают обратный процесс - отошедшие смолоду от веры выходцы из старообрядческой среды на склоне лет возвращаются в места обитания своих одноверцев. Думается, что тщательное изучение «поля» - мест компактного обитания старообрядцев по Енисею - может дать ученым еще немало удивительных археографических открытий.

\section{СПИСОК ЛИТЕРАТУРЫ}

Дутчак, Е. Е. (2008) От «книги читаемой» к «человеку читающему»: из опыта работы археографической экспедиции Томского университета (1986-2006) // Традиционная книга и культура позднего русского средневековья / отв. ред. И. В. Поздеева. Ярославль : Ремдер. 388 с. С. 285-299.

Зольникова, Н. Д. (1992) Современный писатель-старообрядец с Енисея // Традиционная духовная и материальная культура русских старообрядческих поселений в странах Европы, Азии, Америки / отв. ред. Н. Н. Покровский, Р. Моррис. Новосибирск : Наука. 324 с. С. 283-288.

Зольникова, Н. Д. (1998) Урало-сибирские староверы в первой половине XX.: Древние традиции в советское время // История русской духовной культуры в рукописном наследии XVI-XX вв. / отв. ред. Е. К. Ромодановская. Новосибирск : Наука. 316 с. (Археография и источниковедение Сибири. Вып. 18). С. 174-191.

Костров, А. В., Пригарин, А. А. (2018) Фотоматериалы как источник для кросскультурного исследования территориальных групп старообрядцев (Бессарабия, Бурятия, Тува) // Традиционная культура. Т. 19. № 2. С. 38-52.

Покровский, Н. Н. (1984) Путешествие за редкими книгами. М. : Книга, 192 с.

Покровский, Н. Н., Зольникова, Н. Д. (2002) Староверы-часовенные на востоке России в XVIII-XX вв. : Проблемы творчества и общественного сознания. М. : Памятники исторической мысли. 471 с.

Пригарин, А. А., Стороженко, А. А., Татаринцева, М. П. (2020) Актуальное конфессиональное письмо: между историографией и биографией (предварительные замечания к рукописи «Заповедная вера. Книга жития и страданий сымских старообрядцев») //Новые исследования Тувы. № 4. C. 180-200. DOI: www.doi.org/10.25178/nit.2020.4.13

Рыговский, Д. С. (2018) «Правило чашки». Гостеприимство старообрядцев в антропологической перспективе // IV Центральноазиатские исторические чтения. Пространство культур: через призму единства и многообразия : сборник материалов Международной научно-практической конференции (г. Кызыл, 20-23 сентября 2018 г.) / отв. ред. 3. Ю. Доржу, В. М. Дамдынчап, Ю. В. Попков, А. А. Стороженко. Кызыл : Изд-во ТувГУ. 350 с. С. $172-177$.

\footnotetext{
${ }^{1}$ Соколов В. Н. Неповторимый венец : Стихотворения и поэмы [Электронный ресурс] // ЛиTERRAtypa. URL: https://literratura.org/poetry/860-vladimir-sokolov-v-pauzah.html (дата обращения 10.04.2021).
} 
Стороженко, А.А. (2019) Старообрядческие монастыри «енисейского меридиана» в XX веке: истоки, традиции и современное состояние // Новые исследования Тувы. № 1. C. 4-15. DOI: https://doi.org/10.25178/nit.2019.1.1

Шитова, Н. И. (2013) Рукописи старообрядца Т. Ф. Бочкарева в контексте истории и культуры старообрядцев Уймона (XVIII-XXI вв.). Горно-Алтайск: РИО Горно-Алтайского государственного университета. 359 с.

Дата поступления: 08.05.2021 г.

\section{REFERENCES}

Dutchak, E. E. (2008) Ot «knigi chitaemoi» k «cheloveku chitaiushchemu»: iz opyta raboty arkheograficheskoi ekspeditsii Tomskogo universiteta (1986-2006) [From "a readable book" to "a reading person": from the experience of the archaeological expedition of Tomsk University (1986-2006)]. In: Traditsionnaia kniga i kul'tura pozdnego russkogo srednevekov'ia [Traditional book and culture of the late Middle Ages in Russia] / ed. by I. V. Pozdeeva. Yaroslavl', Remder. 388 p. Pp. 285-299. (In Russ.).

Zol'nikova, N. D. (1992) Sovremennyi pisatel'-staroobriadets s Eniseia [A contemporary Old Believer writer from the Yenisei]. In: Traditsionnaia dukhovnaia i material'naia kul'tura russkikh staroobriadcheskikh poselenii v stranakh Evropy, Azii, Ameriki [Traditional spiritual and material culture of Russian Old Believer settlements in Europe, Asia, and America] / ed. by N. N. Pokrovskii and R. Morris. Novosibirsk, Nauka. 324 p. Pp. 283-288. (In Russ.).

Zol'nikova, N. D. (1998) Uralo-sibirskie starovery v pervoi polovine XX.: Drevnie traditsii v sovetskoe vremia [Old Belief in the Urals and Siberia in the first half of the 20th century: Old traditions in Soviet times]. In: Istoriia russkoi dukhovnoi kul'tury $v$ rukopisnom nasledii XVI-XX vv. [A history of Russian spiritual culture in the manuscript heritage of the 16th-20th centuries] / ed. by E. K. Romodanovskaia. Novosibirsk, Nauka. 316 p. Pp. 174-191. (In Russ.).

Kostrov, A. V. and Prigarin, A. A. (2018) Fotomaterialy kak istochnik dlia krosskul'turnogo issledovaniia territorial'nykh grupp staroobriadtsev (Bessarabiia, Buriatiia, Tuva) [Photographic materials as a source for cross-cultural research of Old Believer territorial groups (Bessarabia, Buryatia, Tuva)]. Traditsionnaia kul'tura, vol. 19, no. 2, pp. 38-52.

Pokrovskii, N. N. (1984) Puteshestvie za redkimi knigami [A journey for rare books]. Moscow, Kniga. 192 p. (In Russ.).

Pokrovskii, N. N. and Zol'nikova, N. D. (2002) Starovery-chasovennye na vostoke Rossii v XVIII-XX vv. : Problemy tvorchestva i obshchestvennogo soznaniia [Old believers of the Chasovennoye accord in the East of Russia in the 18th - 20th centuries: Problems of creativity and public consciousness]. Moscow, Pamiatniki istoricheskoi mysli. 471 p. (In Russ.).

Prigarin, A. A., Storozhenko, A. A. and Tatarintseva, M. P. (2020) Aktual'noe konfessional'noe pis'mo: mezhdu istoriografiei i biografiei (predvaritel'nye zamechaniia k rukopisi «Zapovednaia vera. Kniga zhitiia i stradanii symskikh staroobriadtsev») [Contemporary confessional writing between historiography and biography: preliminary notes on the manuscript "Sacred faith. The book of life and sufferings of the Old Believers of Sym"]. New Research of Tuva, no. 4, pp. 180-200. (In Russ.). DOI: www.doi.org/10.25178/nit.2020.4.13

Rygovskii, D. S. (2018) «Pravilo chashki». Gostepriimstvo staroobriadtsev v antropologicheskoi perspektive [“The rule of the cup". The hospitality of the Old Believers in an anthropological perspective]. In: IV Tsentral'noaziatskie istoricheskie chteniia. Prostranstvo kul'tur: cherez prizmu edinstva i mnogoobraziia [4th readings in Central Asian history: The space of cultures through the prism of unity and diversity]. Proceedings of an international conference / ed. by Z. Yu. Dorzhu, V. M. Damdynchap, Yu. V. Popkova and A. A. Storozhenko. Kyzyl, TuvSU Publ. 350 p. Pp. 172-177. (In Russ.).

Storozhenko, A. A. (2019) Staroobriadcheskie monastyri «eniseiskogo meridiana» v XX veke: istoki, traditsii i sovremennoe sostoianie [Old Belief monasteries of the «Yenisei meridian» in the 20th century: origins, traditions and current state]. New Research of Tuva, no. 1, pp. 4-15. DOI: https://doi.org/10.25178/nit.2019.1.1

Shitova, N. I. (2013) Rukopisi staroobriadtsa T. F. Bochkareva $v$ kontekste istorii $i$ kul'tury staroobriadtsev Uimona (XVIII-XXI vv.) [The manuscripts of the Old Believer T. F. Bochkarev in the context of the history and culture of the Old Believers of Uymon, $18^{\text {th }}$ to $21^{\text {st }}$ century]. Gorno-Altaisk, RIO Gorno-Altaiskogo gosudarstvennogo universiteta. 359 p. (In Russ.).

Submission date: 08.05.2021. 